\title{
Os fundamentos da interpretação conforme a Constituição: crônica de uma morte anunciada na Jurisdição Constitucional ${ }^{*}$
}

\author{
The basis of interpretation according to the Constitution: chronicle of a death foretold in
} constitutional jurisdiction

\author{
Emiliane Alencastro** \\ Ivo Dantas ${ }^{* * *}$
}

\begin{abstract}
REFERÊNCIA
ALENCASTRO, Emiliane; DANTAS, Ivo. Os fundamentos da interpretação conforme a Constituição: crônica de uma morte anunciada na Jurisdição Constitucional. Revista da Faculdade de Direito da UFRGS, Porto Alegre, n. 46, p. 161-181, ago. 2021. DOI: https://doi.org/10.22456/0104-6594.112216.
\end{abstract}

\begin{abstract}
RESUMO
A interpretação conforme a Constituição foi cunhada num cenário de fortalecimento da jurisdição constitucional e de aprimoramento da hermenêutica e de técnicas de decisão específicas. A sua teorização no Brasil, no entanto, se deu de maneira conflituosa, tendo sido construída pela conjugação de teses estrangeiras. O presente trabalho pretende demonstrar, por meio de uma pesquisa bibliográfica, que a conflituosa teorização da interpretação conforme só tem como desembocar numa aplicação tormentosa, ocasionando problemas de legitimidade da decisão. Conclui que os fundamentos teóricos da interpretação conforme a Constituição precisam ser revisitados.
\end{abstract}

\section{PALAVRAS-CHAVE}

Interpretação conforme a Constituição. Jurisdição constitucional.

\begin{abstract}
Interpretation according to the Constitution was created in a scenario of strengthening constitutional jurisdiction and improving hermeneutics and specific decision-making techniques. However, its theorization in Brazil took place in a conflictual manner, having been built by the conjugation of foreign theses. The present work intends to demonstrate, by means of a bibliographic research, that the conflicting theorization of the interpretation can only end in a stormy application, causing problems of legitimacy of the decision. It is concluded that the theoretical foundations of interpretation according to the Constitution need to be revisited.
\end{abstract}

\footnotetext{
* Analogia ao texto de Gabriel Garcia Márquez "Crônica de uma morte anunciada". O texto será diversas vezes mencionado ao longo do trabalho.

** Mestranda em Direito (Jurisdição e processos constitucionais) pelo Programa de Pós-Graduação em Direito da Universidade Federal de Pernambuco (PPGD-UFPE). Pesquisadora bolsista da Coordenação de Aperfeiçoamento de Pessoal de Nível Superior (CAPES). Parecerista na Revista Pensamento Jurídico. Pesquisadora do Grupo de Estudos e Pesquisas em Teoria da Separação dos Poderes e a Crise do Sistema Democrático Brasileiro vinculado ao PPGD/UFPE sob a Coordenação da Profa Dra Carina Barbosa Gouvêa. Pesquisadora do Núcleo de Pesquisa em Interpretação e Decisão Judicial (NUPID) vinculado aos Programas de Pós-Graduação em Direito da UFC, Unichristus, Uni7 e Unifor, sob a Coordenação do Prof. Dr. Juraci Mourão Lopes Filho. Advogada.

*** Professor Titular da Faculdade de Direito do Recife - UFPE; Doutor em Direito Constitucional - UFMG; Livre Docente em Direito Constitucional - UERJ; Livre Docente em Teoria do Estado - UFPE; Membro da Academia Brasileira de Letras Jurídicas; Membro da Academia Brasileira de Ciências Morais e Políticas; Presidente do Instituto Pernambucano de Direito Comparado; Presidente da Academia Pernambucana de Ciências Morais e Políticas; Miembro del Instituto IberoAmericano de Derecho Constitucional México); Miembro del Consejo Asesor del Anuario IberoAmericano de Justicia Constitucional, Centro de Estudios Políticos y Constitucionales (CEPC), Madrid; Ex-Diretor da Faculdade de Direito do Recife - UFPE; Membro da Academia Pernambucana de Letras Jurídicas; Fundador da Associação Brasileira dos Constitucionalistas Democráticos; Membro Efetivo do Instituto dos Advogados de Pernambuco; Membro do Instituto Pimenta Bueno - Associação Brasileira dos Constitucionalistas; Professor Orientador Visitante do Programa de Pós-Graduação em Ciências da Saúde, Universidade Federal do Rio Grande do Norte, conforme aprovação do Colegiado, em 31 de maio de 2001; Professor do Curso de Mestrado em Direito da Universidade da Amazônia, UNAMA, Belém do Pará; Juiz Federal do Trabalho - (aposentado); Advogado e Parecerista.
} 


\section{KEYWORDS}

Constitutional jurisdiction. Interpretation according to the Constitution.

\section{SUMÁRIO}

1. Notas introdutórias; 2. O estado da arte da interpretação conforme a Constituição na experiência brasileira; 3 . A categorização da interpretação conforme como vetor interpretativo e como técnica de decisão; 4. Conclusão. Referências. Dados da publicação.

\section{NOTAS INTRODUTÓRIAS}

"No dia em que o matariam, Santiago Nasar levantou-se às cinco e meia da manhã para esperar o navio em que chegava o bispo". Essa conhecida frase inaugural da "Crônica de uma morte anunciada" de Gabriel García Márquez, que antecipa o fim da história a ser contada, sintetiza bem a expectativa quando uma Corte "amola suas facas" para aplicar a interpretação conforme a Constituição. ${ }^{1}$

A jurisdição constitucional foi constituída com a competência de julgar as diversas espécies de processo constitucional (DANTAS, 2016, p. 306). Para tanto, lhes é disposto um "conjunto de técnicas que objetivam garantir a congruência dos atos normativos com a Constituição, preservando a prevalência desta última, mediante atuação fiscalizadora do Poder Judiciário" (LUNARDI, 2013, p. 26).

Com o fim da Segunda Guerra Mundial, a jurisdição constitucional ganha ainda mais força como garante da contenção dos horrores da ditadura e da violação a direitos humanosfundamentais por legisladores serviçais de regimes opressores (CAPPELLETTI, 1980, p. 76). A primazia do Parlamento dá lugar à descrença na sua auto subordinação à Constituição, fortalecendo o estabelecimento de um órgão jurisdicional independente e distinto, inclusive para realizar o controle de constitucionalidade das leis (KELSEN, 2003, p. 108).

Nessa tessitura redemocratizante, a Constituição é posta como paradigma, assumindo um novo significado, fundando um ordenamento jurídico de funcionamento do Estado e de determinação fundamental da vida social. A terceira função do Estado, exercida precipuamente pelo Judiciário, tem destacada importância como agente ativo nos contornos e manutenção da separação dos poderes, sendo inegável a sua relevância política.

\footnotetext{
${ }^{1}$ Referência ao fato de que os assassinos de Santiago Nasar, personagem de "Crônica de uma morte anunciada", amolaram as facas para lhe matar diversas vezes, indicando para inúmeras pessoas que o matariam, sem que ninguém os impedisse.
} 
O pós-Segunda Guerra, para além de outros colapsos, trouxe a crise do positivismo jurídico. Reformula-se a forma de elaborar e realizar o ordenamento jurídico. A pretensão de neutralidade axiológica do positivismo dá lugar a um raciocínio em que se reconhece que os princípios conformam os ordenamentos jurídicos. O direito se desenvolve "equilibrando uma dupla exigência, uma de ordem sistemática, a elaboração de uma ordem jurídica coerente, a outra, de ordem pragmática, a busca de soluções aceitáveis pelo meio, porque conformes ao que lhe parece justo e razoável" (PERELMAN, 2004, p. 328).

Os métodos da específica hermenêutica constitucional também são aprimorados nesse quadrante, a partir da percepção de que a aposição da Constituição como paradigma impõe também uma conformação hermenêutica das disposições. Esse cenário, ainda foi seguido pelo que Lenio Streck denomina de viragem linguística, que implicou a superação do modelo interpretativo sujeito-objeto pela relação sujeito-sujeito, ocasionando um redimensionamento da relação do homem com a sociedade e, por conseguinte, com os textos. Isso gerou a necessidade de aprimorar e desenvolver novas técnicas de interpretação (STRECK, 2018, p. 415).

O passar dos anos, por sua vez, trouxe um novo problema: os efeitos da invalidade de atos inconstitucionais que deixam num gap aqueles que tinham direitos e expectativas legítimas na normativa. A dimensão que a importância da atuação da jurisdição constitucional tomou na garantia da força normativa da Constituição fez necessário também sofisticar as técnicas de decisão, fazendo surgir as sentenças intermédias.

A interpretação conforme a Constituição é um efeito dessa conjuntura, consubstanciando vetor hermenêutico e técnica de decisão cunhada nesse contexto, destinada a indicar o sentido conforme a Constituição quando diante de disposições plurissignificativas, evitando a declaração de invalidade.

Sem adentrar na tormentosa questão da legitimidade do Judiciário para controlar (e alterar o conteúdo de) os atos legislativos e na infausta problemática da decisão jurídica e seus graus de maniqueísmo, o presente artigo pretende demonstrar/relembrar a conflituosa teorização da interpretação conforme que desemboca na já conhecida aplicação tormentosa, ocasionando problemas de legitimidade da decisão. 


\section{O ESTADO DA ARTE DA INTERPRETAÇÃO CONFORME A CONSTITUIÇÃO NA EXPERIÊNCIA BRASILEIRA}

Estudar a interpretação conforme no Brasil significa avaliar as teses estrangeiras introduzidas no cenário nacional após serem buriladas e conjugadas. Diante da atividade homérica que seria fazer referência a tudo o que foi produzido (e não foi pouco), apresentar o estado da arte da interpretação conforme significa ordenar essas ideias, aqui categorizadas em conceito, origem, justificativa e limites.

Sem grandes detalhamentos sobre a razão de assim ser classificada, a interpretação conforme a Constituição é identificada como princípio de interpretação constitucional, integrando a denominada hermenêutica constitucional. ${ }^{2} \mathrm{O}$ conceito comumente empregado de onde também se extraem seus pressupostos - é no sentido de que, diante da polissemia, isto é, diante da pluralidade de sentidos do texto, que gere uma dúvida real sobre seu sentido (BONAVIDES, 2003, p. 518), o que Canotilho (1995, p. 230) denomina de "espaço de decisão aberto", deve ser indicado aquele que é compatível com a Constituição, considerada em bloco, suas normas dispostas e implícitas.

Ao tecer uma análise retrospectiva do instituto, Virgílio Afonso da Silva (2005, p. 3-28) observa que a interpretação conforme tem origem longeva, fazendo menção ao Tribunal Federal suíço, que indicava que uma Corte só pode declarar a nulidade de uma disposição se ela não se prestar a nenhuma interpretação que seja conforme a Constituição. A primeira menção pelo Tribunal Constitucional alemão, ordenamento que exerceu influência considerável no debate brasileiro, teria ocorrido em 1953, indicando que uma lei não pode ser declarada nula se for possível interpretá-la de acordo com a Constituição; pressupõe-se que toda lei seja compatível com a Constituição e isso também implica que, na dúvida de sua constitucionalidade, deve ser feita uma interpretação conforme. Por fim, o autor menciona que é em precedente da Suprema Corte do Estado da Flórida que se encontra um resumo claro de como o Brasil compreende a interpretação conforme: se a disposição admite duas interpretações, em que uma delas a faz

\footnotetext{
${ }^{2}$ Virgílio Afonso da Silva (2005, pp. 115-143) observa que os métodos de interpretação constitucional teriam advindo da referência de Konrad Hesse em manual de direito constitucional. O autor elucida que os princípios de interpretação constitucional (unidade da constituição, concordância prática, conformidade funcional, efeito integrador, força normativa da constituição), no Brasil apresentados como uma unanimidade dentre os alemães, encontra supedâneo apenas na doutrina de Hesse. Tece uma crítica sobre o apego a essa categoria, quando isso não aconteceu nem no ordenamento jurídico alemão.
} 
inconstitucional e outra a mantém válida, a Corte tem o dever de adotar a que salva a lei da inconstitucionalidade.

A doutrina e a jurisprudência costumam justificar a interpretação conforme em dois topoi, convolados em verdadeiros dogmas da interpretação conforme: a garantia de unidade da ordem jurídica e a pretensão de preservar o trabalho legislativo, conservando a presunção (iuris tantum) de constitucionalidade. Na prática, esses elementos são mencionados como mantras, cuja menção repetida parece ser suficiente.

Indicando a unidade como justificativa ${ }^{3}$ diversas vezes a intepretação conforme é aplicada por meio da narrativa da imperatividade da Constituição frente a todo o ordenamento, deflagrando a necessidade de optar por uma interpretação que é consentânea com a Constituição ao alvedrio de outra, confundindo a unidade da ordem com outro postulado, o da supremacia constitucional. ${ }^{4}$ Diversas vezes o postulado da unidade é também indicado para justificar o aceite à migalha de uma saída menos ruim, por meio da conservação da norma. Diz-se estar optando por uma interpretação ao alvedrio de outra possível que faria a disposição inconstitucional, causando um gravame àqueles que possuíam expectativas legítimas defluentes da lei mais intenso do que se a disposição ficasse hígida no sistema.

A justificação na preservação do trabalho legislativo comumente se embasa na presunção de constitucionalidade das normas. Diante de uma faísca de constitucionalidade, o intérprete deve tacar a ela fogo, produzindo uma conclusão pela constitucionalidade, homenageando a atividade legislativa. Elidir a presunção de constitucionalidade demandaria um exercício cognitivo e de julgamento mais detalhado, sendo a inconstitucionalidade o tom mais escuro, a última hipótese, a saída quando não tem mais jeito.

O problema é que, diante da multiplicidade de valores constitucionais, soa como se fosse possível salvar quase tudo. Em paralelo, há evidência de que muitas vezes o intérprete vai muito além da mera preservação do trabalho legislativo ou simplesmente intenta desfazê-lo,

\footnotetext{
${ }^{3}$ A unidade da ordem jurídica parte da necessidade de inexistirem contradições no ordenamento, consubstanciando um postulado normativo (ÁVILA, 1999, p. 164). É um dado complexo porque as fontes jurídicas são diversas. Adotada a tese de construção escalonada, as normas não estão todas no mesmo plano; as inferiores dependem das superiores, cujo topo (norma superior) é a norma fundamental. Essa norma fundamental é o termo unificador das normas que compõem o ordenamento jurídico, estando consubstanciado na atribuição ao poder constituinte de produzir normas jurídicas e o dever de todos de obedecê-las. A norma fundamental seria pressuposta e não escrita (BOBBIO, 1995, pp.48-49 e pp.58-59).

${ }^{4}$ A questão da unidade da ordem em Tércio Sampaio é inserida no debate acerca do plano da validade. O autor observa que a validade é um conceito relacional fazendo surgir a questão de como chegamos ao todo normativo como um conjunto globalmente vinculante, nesta está a da unidade do sistema, e a questão do ponto de Arquimedes no ordenamento, validante de todas as normas, nesta está o fundamento de validade. (FERRAZ JR., 2018).
} 
produzindo uma integração ou uma verdadeira revisão da disposição legal. ${ }^{5}$ Não suficiente, a presunção de constitucionalidade é um juízo que exclui as normas pré-constitucionais, uma vez que não é possível presumir fidelidade ao que ainda não existe.

Até aqui, o cenário já é tormentoso. Mas nada se equipara à teorização dos limites à interpretação conforme, que geralmente têm como foco conter a atividade judicante. Caminho para conter a criatividade excessiva, parte-se da ideia de que a interpretação realizada pela função jurisdicional não pode adentrar nos campos destinados ao legislador e ao administrador. Comumente identificam-se os limites na expressão literal da lei e na vontade do legislador, elementos que são estabelecidos geralmente como mecanismos para impedir a atuação da jurisdição como legislador positivo. ${ }^{6}$ Aqui, há claramente uma cizânia teórica no instituto: foi criado pela jurisdição, num momento de fragilização do positivismo jurídico, mas seus limites são cunhados sob a égide da hegemonia da lei, de crença numa descrição objetiva do direito.

Dispor o sentido literal do texto como limite impõe recusar a interpretação contra legem (BARROSO, 2008, p. 198). Partindo das premissas de que o texto é o enunciado linguístico e a norma é o produto da interpretação do enunciado, isso implica que a norma extraída da disposição não pode ser contrária aos sentidos mínimos das palavras. A linguagem é um dado muito relevante para o Direito. O sentido literal, especialmente numa língua rica como a portuguesa, pode ser plurissignificativo também. Isso impõe que o número de interpretações admissíveis de um texto é limitado, mas não é determinado, sendo certo que o intérprete deve dizer como algo é a partir do que o Parlamento indicou.

A ideia do sentido literal comumente faz a doutrina se remeter, de maneira velada ou explícita, a um método tradicional de hermenêutica, especificamente a interpretação gramatical proposta por Savigny no começo do século XIX, criado para resolver problemas sintáticos,

\footnotetext{
${ }^{5}$ Mencione-se o caso da presunção de inocência (ADCs 43 e 44), que levou ao STF, em 2016, a análise do art. 283 do CPP que "Ninguém poderá ser preso senão em flagrante delito ou por ordem escrita e fundamentada da autoridade judiciária competente, em decorrência de sentença condenatória transitada em julgado ou, no curso da investigação ou do processo, em virtude de prisão temporária ou prisão preventiva". Impulsionado por ações declaratórias de constitucionalidade, os dispositivos da Constituição utilizados como parâmetro foram os incisos LVII e LXI do art. $5^{\circ}$, que dizem basicamente o mesmo do art. 283 do CPP. O STF seguiu o voto do Ministro Fachin no seguinte sentido: "Voto por declarar a constitucionalidade do art. 283 do Código de Processo Penal, com interpretação conforme à Constituição, que afasta aquela conferida pelos autores nas iniciais dos presentes feitos segundo à qual referida norma impediria o início da execução da pena tão logo esgotadas as instâncias ordinárias, assentando que é coerente com a Constituição o principiar de execução criminal quando houver condenação confirmada em segundo grau, salvo atribuição expressa de efeito suspensivo ao recurso cabível". Como o dispositivo do CPP dizia o mesmo da Constituição, mas pretendendo dar outro sentido à norma, o STF realizou "interpretação conforme", produzindo uma verdadeira revisão do dispositivo.

${ }^{6}$ É importante mencionar que para Rui Medeiros (1999, p. 290) a interpretação conforme serve também para determinar, dentre as várias interpretações conformes à Constituição, a que melhor corresponde à decisão do legislador constitucional, o que denomina de "interpretação orientada para a Constituição".
} 
indicando a impossibilidade de violar a literalidade do texto. Isso prova o que Karl Larenz (1983, p. 411) já advertia: os métodos tradicionais também são úteis para a interpretação constitucional, inclusive porque enfrentam muitos dos mesmos problemas.

No que tange à interpretação conforme, parece mais adequado indicar que o limite, na verdade, seria a existência de uma disposição unívoca e inequívoca. Se o texto for unívoco, não há polissemia; se for inequívoco, não há dúvida sobre o sentido, carentes os pressupostos da interpretação conforme. Em sua natureza, a interpretação conforme exige a existência de dúvida diante de múltiplos significados e aqui adverte-se que a precisão de um texto pode depender muito mais de uma conjuntura sistemática do que da literalidade das palavras. Se o sentido for unívoco e/ou inequívoco, ou ele é constitucional ou inconstitucional, demandando uma sentença pura, impedindo a realização de interpretação conforme.

Em todo caso, adotado o sentido literal como limite, tem-se que o intérprete estaria vinculado a um texto preexistente, não podendo atribuir a ele um significado a seu gosto. ${ }^{7}$ Ao legislador e ao intérprete se apresentam dois campos de discricionariedade distintos, sendo o do intérprete menor em extensão, razão pela qual, em sede da jurisdição e da administração, as decisões devem ser motivadas sob pena de nulidade. ${ }^{8}$ A questão é que esse limite perde eficácia quando é a última (ou única) instância que (des)motiva a decisão. Esse ponto é relevante, inclusive, porque diversas vezes o Supremo Tribunal Federal profere decisão de interpretação conforme indicando sentido diverso do texto legal. ${ }^{9} \mathrm{Em}$ paralelo, quando o texto é lacunoso, exsurgindo a necessidade de uma integração (conforme a Constituição), o sentido literal obviamente também não é resolutivo. ${ }^{10}$

\footnotetext{
7 "A interpretação é, num certo sentido, produção de normas". Apesar disso, "uma coisa é "produzir uma norma" no sentido de interpretar - isto é, decidir o significado de - um texto normativo preexistente; outra é "produzir uma norma" no sentido de formular um texto normativo ex novo". (GUASTINI, 2005, pp. 221-222).

${ }^{8}$ Sobre as decisões administrativas, especialmente depois das alterações promovidas pela Lei n. 13.655/2018 à LINDB, especialmente diante do disposto no art. 20, resta inconteste a necessidade de que as decisões administrativas sejam motivadas, demonstrando a necessidade e adequação de medida imposta ou de invalidação de ato, contrato, ajuste, processo ou norma administrativa, considerando também as alternativas possíveis.

${ }^{9}$ Mencione-se a ADI $6039 \mathrm{MC} / \mathrm{RJ}$, em que o STF avaliou a constitucionalidade de norma estadual que previa que, se a vítima do estupro for pessoa do sexo feminino menor de 18 anos, esta vítima deveria ser examinada, obrigatoriamente, por uma legista mulher, que irá fazer a perícia. O STF concedeu medida cautelar em ADI para dar interpretação conforme a Constituição a esse dispositivo. Segundo o STF, as crianças e adolescentes do sexo feminino vítimas de violência deverão ser, obrigatoriamente, examinadas por legista mulher, mas desde que isso não importe retardamento ou prejuízo da diligência. Resta evidente que o sentido dado deixou de ser "obrigatoriamente" para ser "preferencialmente". BRASIL. Supremo Tribunal Federal (Plenário). ADI 6039 MC/RJ. Rel.: Min. Edson Fachin, 13 de março de 2019. Info. 933.

${ }^{10} \mathrm{~A}$ menção à integração conforme é um dado a ser mencionado quando se trata da interpretação como processo (não como resultado).
} 
O limite denominado "vontade do legislador" não se distancia tanto do primeiro porque “a lei - dispositivo legal - é uma declaração da vontade do legislador" (REALE, 2002, p. 200). Por sua vez, é um elemento que exige a avaliação das teorias objetiva e subjetiva. De maneira muito resumida, a teoria subjetiva, elaborada na era do codicismo, dispõe que a interpretação deve considerar a vontade do legislador (mens legislatoris), o que ele pretendia conferir à disposição, com subsídio na análise semântica e nos elementos históricos comuns à edição. Em Posner (1983, p. 817), ao aplicar a lei, o magistrado deve pensar uma maneira de penetrar na mente dos legisladores, imaginando como eles gostariam que o dispositivo fosse aplicado ao caso sob julgamento. Na teoria objetiva, a lei ganha autonomia perante o legislador, sendo o resultado de um querer social, isto é, possuindo vontade própria (mens legis). A lei teria "uma vontade transformada em palavras, uma força constante e vivaz, objetivada e independente do seu prolator” (MAXIMILIANO, 1980). Assim, a disposição textual tem uma importância reavivada, a ser inserida num contexto social. Essa tensão entre o pensamento do legislador, enquanto fator subjetivo, e a lei como produto autônomo do espírito do povo, enquanto fator objetivo, foi a tônica do desenvolvimento da ciência jurídica como teoria da interpretação (FERRAZ JR, 2018, p. 278).

A teoria subjetiva foi posta em xeque pela teoria objetiva, uma vez aperfeiçoada a teoria da interpretação. Em paralelo, como o texto legal já é um limite objetivo na teorização da interpretação conforme, e identificar o sentido mais adequado à Constituição é o seu objeto, a tese da vontade objetiva da lei perde relevância. Em todo caso, a busca pelo que o legislador/a lei quis dizer é em demasia problemática e, num cenário perfeito, se o intérprete consegue identificá-la, seja a partir de uma percepção subjetiva ou objetiva dessa vontade, não há que se falar em polissemia. Se é possível precisar a vontade, não há dúvida de sentido, não cabendo realizar interpretação conforme.

Acaso se entenda que a teoria subjetiva não foi ultrapassada, já que não é unânime na doutrina sua decadência, para além da dificuldade de chegar a essa "vontade", esse limite impõe, em verdade, a realização de uma interpretação retrospectiva. Tal qual desenvolve Lenio Streck (1995, p. 276), "interpretar o texto novo de maneira a que ele não inove nada, mas ao revés, fique tão parecido quanto possível com o antigo". É um modo covarde de interpretar, obrigando o intérprete a desconsiderar o novo contexto no qual está inserido. Essa ideia vai, inclusive, de encontro ao que preconiza o princípio da interpretação conforme, que ordena considerar a Constituição em bloco como parâmetro, o que abrange também o que não está 
expresso. A interpretação deve permitir também uma visão prospectiva da norma, possibilitando a apreciação de fatos e valores em concreto.

Em paralelo, rememore-se que a imutabilidade relativa é uma das prerrogativas da Constituição. Trata-se de qualidade que vive uma simbiose: se por um lado impõe limite às mudanças, por outro demonstra a necessária legitimidade e adaptação constitucional à realidade (que é cambiante). ${ }^{11} \mathrm{~A}$ imutabilidade relativa é consequência da rigidez que, por sua vez, decorre da supremacia constitucional, sendo também prerrogativa conformadora de uma supremacia formal, que consubstancia a superioridade hierárquica da Constituição perante todas as normas infraconstitucionais. A relativização da imutabilidade consubstancia uma solenidade no procedimento de transformação formal que vincula os atos infraconstitucionais a fim de estabilizar as opções constitucionais mantendo a sua legitimidade. Isso indicia a necessidade de a Constituição comportar novas significações para se perfazer no tempo.

Em paralelo, diante da atual tendente postura ativa do intérprete, também surge a questão de se é possível corrigir essa vontade por meio da interpretação. Para Leo Brust (2009, p. 523), o juiz pode superar a vontade do legislador para aplicar a Constituição nos casos em que o preceito constitucional for claro, unívoco ou a decisão não for contra legem e for evitar repercussões sociais graves. Para o autor, isso não seria invadir a competência do Legislativo, mas perceber que o dogma do legislador negativo já não condiz com o que se espera da jurisdição constitucional. A fiscalização da constitucionalidade não pode prescindir de mecanismos que garantam a plena normatividade da Constituição, ainda que determinada interpretação não esteja totalmente de acordo com a suposta vontade originária do legislador. Defende que não se está diante de criação do direito, mas de aplicação da Constituição.

À toda evidência, esses limites decorrem da teoria da separação dos poderes conjugada com a tese do legislador negativo, em que o juiz constitucional, no máximo, elimina norma, mas não cria. A interpretação conforme é teorizada para nortear e limitar o intérprete e, mesmo assim, é constantemente utilizada para revisar e criar direito, o que não consubstancia um erro propriamente dito, mas denota a dissonância com a teoria. Essa conjuntura é perfeita para formação de decisões incoerentes, causando um déficit de legitimidade.

11 "Uma geração pode obrigar a si mesma enquanto a maioria continua viva; quando esta desaparece, outra a substitui, mantém os direitos e poderes que seus predecessores antes retiveram, e pode modificar as leis e instituições para satisfazer a si mesma. Nada é, pois, imutável senão os direitos inerentes ao homem e dele inalienáveis." (JEFFERSON, 1964, p. 119-120). 
Demonstrado o campo insólito no qual está inserido o tema, esses elementos se convolam em terra arrasada dos invocadores pomposos e orgulhosos de seus castelos de areia. Cada autor que enfrenta, inclusive o próprio Supremo Tribunal Federal na fundamentação de suas decisões, demonstra o modo dissonante com a teoria com a qual o instituto é aplicado. É como se todo mundo estivesse avisando, mas ninguém está fazendo nada. ${ }^{12}$

\section{A CATEgORIZAÇÃO DA INTERPRETAÇÃO CONFORME COMO VETOR INTERPRETATIVO E COMO TÉCNICA DE DECISÃO}

A interpretação conforme é por vezes identificada como princípio de hermenêutica constitucional, método de interpretação das leis infraconstitucionais e também como técnica de decisão no controle de constitucionalidade (MORAIS, 2005, p. 327). Há um dissenso entre os doutrinados sobre essa categorização. Em todo caso, as teses são construídas com a menção a diversos julgados e outras tantas doutrinas. ${ }^{13}$ Nesse tônus, o tema tem reflexos na hermenêutica jurídica e na fiscalização da constitucionalidade.

Enquanto vetor hermenêutico, a interpretação se dar em conformidade com a Constituição é uma ideia que beira o trivial, diante da obviedade de que, num Estado Constitucional, toda interpretação jurídica deve considerar os valores da Constituição como norte (DA SILVA, 2005). Interpretar é conduzir a um resultado constitucionalmente adequado; significa conferir sentido e alcance às normas jurídicas à luz da Constituição, mediante um processo racional e controlável que cria, desse modo, certeza e previsibilidade jurídica (HESSE, 1992, p.35).

O seu fim é instrumentalizar a materialização da supremacia constitucional e da força normativa da Constituição, permitindo que se realize o que é denominado de filtragem hermenêutico-constitucional; assim, é um instrumento de constitucionalização dos textos infraconstitucionais (STRECK, 2018). Utilizando as sintéticas palavras de García de Enterría

\footnotetext{
12 Referência à "Crônica de uma morte anunciada", em que toda a população sabia que Santiago Nasar seria assassinado e, mesmo assim, ninguém faz nada para impedir ou avisar.

${ }^{13}$ Para Xavier, a distinção em categorias sequer possui relevância prática (XAVIER, 2013, p. 21). Para Marinoni, a interpretação conforme seria técnica de decisão, enquanto a interpretação de acordo com a Constituição seria a técnica de hermenêutica (MARINONI, 2010, pp. 174-177). Para Virgílio Afonso da Silva, o princípio referido não é método de hermenêutica constitucional, pois serve apenas para interpretar textos infraconstitucionais (à luz da Constituição) (DA SILVA, 2006, p. 192). Para Ribeiro, trata-se apenas de critério hermenêutico, não possuindo natureza de técnica decisória (RIBEIRO, 2009, p. 159). Para José Levi Amaral Junior, seria apenas técnica de hermenêutica, indicando que em sede do controle de constitucionalidade se trataria de declaração parcial de nulidade sem redução de texto (AMARAL JUNIOR, 2009, p. 1123-1128).
} 
(1982, p. 95), “es una consecuencia derivada del carácter normativo de la Constitución y de su rango supremo y está reconocido en los sistemas que hacen de ese carácter un postulado básico". A manifestação basilar de força normativa da Constituição é justamente a necessidade de que toda ordem jurídica seja lida a partir dela e passada pelo seu crivo (MEDEIROS, 1999, p. 297).

Para tanto, a interpretação conforme se opera como uma interpretação sistemática que impõe a leitura do sistema jurídico a partir da Constituição. Isso porque "em sistemas que atribuem à Constituição uma força normativa plena e o estatuto de Lei Fundamental, o elemento sistemático-teleológico não pode, à partida, dispensar o apelo à Constituição" (MEDEIROS, 1999, p. 297). Assim, "define-se como uma modalidade de interpretação 'secundum constitutionem', consistindo um critério de recorte dogmático inerente a uma operação hermenêutica de natureza sistemático-teleológica” (MORAIS, 2005, p. 326).

Para além de permitir uma leitura das normas a partir da Constituição, a interpretação conforme perpassa a interpretação da própria Constituição. A definição do sentido de lei cuja redação é ambígua ou de sentido indeterminado é delineada a partir da utilização da Constituição não só como "norma-parâmetro", mas também como "norma de conteúdo" (HESSE, 1991, p. 50-51).

No Brasil, a interpretação conforme é comumente identificada como princípio de interpretação constitucional. ${ }^{14}$ Outrossim, não se trata de princípio porque consubstancia norma metódica, que estrutura a interpretação e a aplicação de princípios e regras. Os princípios são normas imediatamente finalísticas, que têm como qualidade principal a determinação de um fim juridicamente relevante. ${ }^{15}$

A interpretação conforme se apresenta como um critério normativo, uma vez que consubstancia diretriz para aplicação de outra norma, ${ }^{16}$ apontando para a preferência de sentido que seja em conformidade com a Constituição. ${ }^{17}$ Destina-se a todo intérprete, a todas as "forças

\footnotetext{
${ }^{14}$ Os métodos de interpretação constitucional, por sua vez, em concordância com Canotilho que reestruturou o pensado por Böckenförde, seriam os métodos hermenêutico clássico, tópico-problemático, científico-espiritual, hermenêutico-concretizador e normativo-estruturante (CANOTILHO, 1995, p. 1084 e ss).

${ }^{15}$ A interpretação e aplicação de princípios demandam uma avaliação de correção entre o estado de coisas posto como fim e os efeitos decorrentes da conduta havida como necessária (ÁVILA, 2005, p. 88 e ss).

16 "O critério responde à seguinte pergunta: como/mediante que/por que se deve entre dois ou mais elementos envolvidos ser escolhido um deles ou como/mediante o que se pode distinguir dois elementos? Um critério normativo, [...], consubstancia, não um princípio, mas uma meta-regra de aplicação de outras normas. Meta-regra justamente porque atua "sobre" a aplicação de outras regras" (ÁVILA, 1999, p. 166).

17 "É possível segundo os demais critérios de interpretação, há-de preferir-se a qualquer outra em que a disposição viesse a ser inconstitucional. A disposição nesta interpretação é então, nesta interpretação, válida. Disto decorre,
} 
pluralistas públicas" (HABERLE, 2002, p. 19): ao administrador, aplicador da lei por excelência; à atividade parlamentar, em especial mencione-se a comissão parlamentar de constituição e justiça; a todos os juízes, em demandas judiciais comuns e nas que tenham o controle de constitucionalidade como objeto, seja como pedido ou como causa de pedir, inclusive aos órgãos fracionários e aos juízos monocráticos.

Enquanto critério normativo, quando diante de diversos sentidos, sendo um adequado à Constituição e outros não, o postulado normativo hermenêutico que o impulsiona é o da hierarquia, razão pela qual é também uma forma de concretizar a supremacia constitucional; quando diante da multiplicidade de interpretações de acordo com a Constituição, o postulado normativo hermenêutico que o impulsiona é o da coerência, diante da relação de dependência entre as normas. ${ }^{18}$ Esses dois postulados, que conformam a interpretação conforme enquanto critério normativo, meta-regra de aplicação de outras regras, são complementares na compreensão do ordenamento jurídico. ${ }^{19}$

Para além de ser um critério normativo impulsionado por postulados hermenêuticos, a interpretação conforme pode também ser impulsionada por postulados normativos aplicativos. Quando a interpretação conforme é utilizada para deflagrar a inconstitucionalidade de interpretação, apresenta-se estimulada por uma "condição formal ou estrutural de conhecimento concreto (aplicação) de outras normas", por uma condição normativa para a devida aplicação do direito (ÁVILA, 1999, p. 170). E é disso que se extrai que a interpretação conforme utilizada para verificar a relação abstrata das normas no sistema jurídico, em uma demanda específica, deve considerar os postulados aplicativos, como a ponderação, a concordância prática, a proporcionalidade, $v . g$.

\footnotetext{
então que de entre as várias interpretações possíveis segundo os demais critérios sempre obtém preferência aquela que melhor concorde com os princípios da Constituição. «Conformidade à Constituição» é portanto, um critério de interpretação" (LARENZ, 1997, pp. 480-481).

18 "Os postulados normativos são entendidos como condições de possibilidade do conhecimento do fenômeno jurídico. Eles, também por isso, não oferecem argumentos substanciais para fundamentar uma decisão, mas apenas explicam como (mediante a implementação de quais condições) pode ser obtido o conhecimento do Direito. As condições de possibilidade do conhecimento jurídico reveladas pela hermenêutica jurídica consubstanciam postulados normativos: o conhecimento da norma pressupõe o do sistema e o entendimento do sistema só é possível com a compreensão das suas normas (postulado da coerência); [...]" (ÁVILA, 1999, p. 165).

${ }^{19}$ Aqui é importante mencionar que os postulados são metanormas que se situam num segundo grau e estabelecem a estrutura de aplicação de outras normas, princípios e regras. "A violação de um postulado consiste na nãointerpretação de acordo com sua estruturação". Os postulados normativos hermenêuticos destinam-se à compreensão geral do Direito; os postulados normativos aplicativos são normas metódicas que estruturam a interpretação e a aplicação de princípios e regras, exigindo relações entre os elementos com base em critérios (ÁVILA, 2005, p. 88 e ss).
} 
Em todo caso, adotado como princípio ou como critério normativo, é importante reconhecer que a realidade é muito mais complexa que a teorização. Os desafios que os aplicadores da Constituição enfrentam são complexos e estão em constante transformação. "Daí a necessidade, de resto comum a todos os instrumentos hermenêuticos, de que todos eles sejam manejados à luz de casos concretos, naquele interminável balançar de olhos entre objeto e método, realidade e norma" (COELHO, 2002, p. 185).

É importante ainda fazer menção à ambiguidade oriunda do termo adotado "interpretação conforme a Constituição" - utilizado para se referir ao processo de interpretar de acordo com a Constituição e para o resultado desse processo - a norma extraída da disposição à luz da Constituição -. ${ }^{20}$

Enquanto processo, o seu start pressupõe que a interpretação tem por base o texto. Os textos são, portanto, a matéria-prima do intérprete e eles são comumente genéricos e compostos por palavras de múltiplos significados, para atingir o maior número de situações possíveis. Por falha do legislador, podem também ser ambíguos. Por equívoco ou eloquência, podem ser lacunosos e omissos. Não suficiente, superada a crença num texto omnicompetente, capaz de ser completo e abrangente, há ainda as normas implícitas, que são deduzidas do ordenamento. Há também os casos de antinomia diante da pluralidade de normas incompatíveis, outra morte anunciada no Direito. Verificada a existência de sentidos plurissignificativos na disposição legal, a interpretação conforme no processo de interpretação servirá como um filtro constitucional, identificando quais interpretações são alternativas possíveis.

O resultado do processo interpretativo é a extração da norma, podendo ser declarativo, restritivo ou extensivo (NADER, 2014, p. 313). O cenário ideal é aquele em que o resultado é a declaração do que está disposto na lei, e isso exige que o legislador tenha utilizado as palavras adequadas aos significados pretendidos. Esse resultado não pode ser instrumentalizado pela interpretação conforme, porque ela exige dúvida real sobre o sentido. A interpretação conforme tem lugar numa "interpretação extensiva ou restritiva à redução (eliminando os elementos inconstitucionais do preceito ou do ato) e, porventura, à conversão (configurando o ato sob a veste de outro tipo constitucional)" (MIRANDA, 2008, p. 331). Mas nenhum desses resultados pode consubstanciar revisão de Direito, ao alvedrio da disposição textual; o resultado restritivo ou extensivo pressupõe o texto como ponto de partida.

\footnotetext{
${ }^{20}$ Há uma distinção entre a disposição e a norma. O texto é o que está disposto, a norma é o significado do texto extraído pelo intérprete. A norma seria, portanto, o produto da interpretação da disposição (MULLER, 2005).
} 
Aqui é importante considerar o aviso de Marcelo Neves (2001, p. 366) de que "na interpretação jurídica não se trata de extrair arbitrariamente de uma infinidade de sentidos dos textos normativos a decisão concretizadora, nos termos de um contextualismo decisionista", sendo importante destacar também que é “inaceitável a concepção ilusória de que só há uma solução correta para cada caso, conforme os critérios de um juiz hipotético racionalmente justo”. É possível que haja mais de uma decisão justificável, considerando os princípios e regras constitucionais. "O problema está exatamente em delimitar as fronteiras entre as interpretações justificáveis e as que não são 'atribuíveis' aos textos constitucionais e legais no Estado Democrático de Direito".

Enquanto vetor hermenêutico, instrumentalizador da fixação do sentido e do alcance de normas jurídicas, mediante um processo racional e controlável, a interpretação conforme, seu processo e resultado, deve integrar a fundamentação da decisão, constituindo sua ratio decidendi. A sua utilização implica a produção de uma sentença com efeito interpretativo (DÍAZ REVORIO, 2011, p. 45), pouco teorizada no Brasil. A interpretação conforme, nessa tônica, pode ser utilizada em diversas técnicas de decisão, sendo importante destacar a necessária formação da fundamentação da decisão com acuidade para que seja possível compreender a saída dada.

Enquanto técnica de decisão de controle de constitucionalidade, a interpretação conforme diz respeito ao tipo de sentença produzida após a verificação de (in)compatibilidade material das interpretações possíveis com a Constituição. Aplicada a interpretação conforme enquanto vetor interpretativo impulsionado por postulados normativos aplicativos, em sendo a constitucionalidade a questão principal da demanda, verificada por uma Corte Constitucional, faz-se premente que a técnica de decisão também seja a interpretação conforme.

No ordenamento brasileiro, enquanto técnica de decisão, encontra previsão na Lei n. 9.868/99, que também estabelece a eficácia erga omnes e o efeito vinculante da decisão que utiliza essa técnica (parágrafo único do art. 28 da Lei 9.868/99). Mas antes dessa previsão legal, e até mesmo da promulgação da Constituição vigente, o Supremo Tribunal Federal fez menção à interpretação conforme como técnica de decisão no controle abstrato. ${ }^{21}$

Possuir eficácia erga omnes significa que a decisão se estende a todos os feitos em andamento, impedindo que seja feito um juízo diverso do disposto na decisão (DA SILVA, 2004, p. 60). Embora não se confunda com o instituto da coisa julgada, diz-se que a eficácia

${ }^{21}$ BRASIL. Supremo Tribunal Federal. RP 1417. Rel.: Min. Moreira Alves, 15 de abril de 1988. 
contra todos se restringe ao disposto no dispositivo do julgado, limitando a extensão do que se tem por impedido de juízo diverso (MENDES; COELHO; BRANCO, 2009, p. 597).

O efeito vinculante, por sua vez, significa a vinculação dos demais órgãos do Poder Judiciário (exceto o pleno do Supremo) e à Administração Pública direta e indireta, nas esferas federal, estadual e municipal. Impõe um dever de aplicar o precedente, inclusive de ofício. O art. 927, I, do CPC/15 também prevê que as decisões do STF em controle concentrado de constitucionalidade produzem efeito vinculante. O que vincula é a norma jurídica geral - tese jurídica, a ratio decidendi - estabelecida na fundamentação da decisão judicial, obrigando que os órgãos jurisdicionais adotem a mesma tese jurídica na sua fundamentação. No mesmo sentido está o enunciado n. 168 do FPPC, que estabelece que "os fundamentos determinantes do julgamento de ação de controle concentrado de constitucionalidade realizado pelo STF caracterizam a ratio decidendi do precedente e possuem efeito vinculante para todos os órgãos jurisdicionais".

$\mathrm{Na}$ forma como foi teoricamente pensada, a interpretação conforme, enquanto técnica de decisão, produziria uma sentença de improcedência sobre a inconstitucionalidade, o que, à luz da ambivalência, implica declarar a constitucionalidade, desde que seja utilizado o sentido apontado como adequado com a Constituição. Nessa decisão, há um juízo positivo, em que se declara que a norma é constitucional; e um juízo negativo, por meio do rechaço de sentidos inadequados ao alvedrio do compatível com a Constituição, apondo-se a sua consideração como condição.

Enquanto técnica de decisão, a interpretação conforme só tem lugar no controle abstrato. O procedimento previsto para o controle abstrato, em que o juízo sobre a constitucionalidade de norma é o mérito da demanda, o pedido a ser enfrentado, autoriza a interpretação conforme enquanto técnica de decidir. No controle concreto, o enfrentamento da questão prejudicial constitucional está inserido na fundamentação da decisão. O mérito da demanda se destina à tutela de direito subjetivo, sendo a questão constitucional uma prejudicial que será enfrentada como caminho para resolver a causa principal. A sentença a ser produzida é uma sentença tradicional, que até pode ter efeito interpretativo, mas o seu dispositivo resolverá a causa principal e terá eficácia apenas para as partes.

Aqui é importante mencionar que o controle difuso, realizado por qualquer juiz ou tribunal, no bojo de um processo subjetivo, quando realizado por um colegiado exige o respeito à cláusula de reserva de plenário, que estabelece a necessidade do voto da maioria absoluta de seus membros ou do órgão especial para declarar a inconstitucionalidade de lei ou de ato 
normativo (art. 97 da CRFB/88). Nessa hipótese, a questão constitucional, que é mera causa de pedir na demanda, é deslocada para o pleno ou órgão especial, que avaliará a disposição de maneira objetiva. Para aplicar a interpretação conforme nessa tessitura, o Supremo tem precedentes no sentido de não ser exigível a reserva de plenário porque esta se aplica à declaração de inconstitucionalidade. Fundamenta que não é a disposição legal que é objeto de controle, mas uma interpretação, atividade que é atribuição inerente à função jurisdicional. ${ }^{22}$

Desse cenário, impõe-se que, no Brasil, no controle difuso, a interpretação conforme só pode ser vetor interpretativo, não pode ser técnica de decisão, salvo se feito pelo Supremo. A interpretação conforme realizada pelo Supremo Tribunal Federal, seja por meio de sentença interpretativa ou de efeito interpretativo, isto é, seja como vetor interpretativo ou como técnica de decisão, tem eficácia erga omnes e efeitos vinculantes. Em sede do Supremo, o problema não é a categorização, mas o alcance do julgado. Em paralelo, há uma série de questões que precisam ser enfrentadas, como a (im)possibilidade de reavaliar as interpretações afastadas e até mesmo se a aplicação da interpretação conforme numa demanda subjetiva não sofre limitações cognitivas.

Aplicado como técnica de decisão, o resultado da interpretação conforme deveria integrar o dispositivo de uma sentença interpretativa, cuja teorização ainda é pouco adaptada para o ordenamento brasileiro. Por mais que a tese jurídica disposta na fundamentação possua eficácia vinculante, como a disposição legal é mantida, a Corte deve declarar a sua constitucionalidade, indicando a interpretação adequada na parte dispositiva, porque é nela que se apõe a resolução do problema levado a juízo, após a cognição e o julgamento da questão principal.

Na prática, por sua vez, raramente é possível detectar se a Corte utilizou a interpretação conforme como técnica de decisão ou como vetor hermenêutico. Utiliza-se a intepretação conforme para dizer o que pensa sobre norma, aplica-a para dar procedência ao pedido de inconstitucionalidade e a confunde com declaração parcial de inconstitucionalidade sem redução de texto.

\footnotetext{
${ }^{22}$ BRASIL. Supremo Tribunal Federal (1. Turma). Rcl 24284/SP. Rel.: Min. Edson Fachin, 22/11/2016. Info. 848.
} 


\section{CONCLUSÃO}

No Brasil, a interpretação conforme a Constituição é teorizada de maneira conflituosa, consistindo num emaranhado à brasileira de teses estrangeiras. Em que pese ter surgido de decisões de Tribunais Constitucionais em fortalecimento, foi cunhada para a salvar a norma da inconstitucionalidade, homenageando o trabalho do legislador.

Diante tamanha confusão teórica, a compreensão e aplicação do instituto só poderia ser tremendamente complicada. Uma superficial análise dos elementos fundantes da interpretação conforme, como a feita neste trabalho, já demonstra que se encontra teorizado em elementos conceituais oriundos de momentos distintos da ciência jurídica e de sistemas jurídicos diferentes, havendo uma série de incompatibilidades, inclusive com o estágio atual da hermenêutica jurídica.

Esse desacordo teórico demonstra que há uma crise, uma morte anunciada da teoria, porque é a teoria que morre quando a prática é reiteradamente diferente dela. É inconteste que os fundamentos teóricos da interpretação conforme precisam ser revisitados e reformulados. Todos sabem o que vai acontecer quando a interpretação conforme vai ser aplicada; "Muitas das pessoas que estavam no porto sabiam que Santiago Nasar ia ser morto". ${ }^{23}$ A pena é que essa certeza não consubstancia segurança jurídica, muito pelo contrário. E ninguém faz nada.

\section{REFERÊNCIAS}

AMARAL JUNIOR, José Levi. Intepretação conforme a Constituição e declaração de inconstitucionalidade sem redução de texto. In: BONAVIDES, Paulo; MIRANDA, Jorge; AGRA, Walber de Moura (org.). Comentários à Constituição Federal de 1988. Rio de Janeiro: Forense, 2009. p. 1617-1628.

AMARAL, Maria Lúcia. As decisões intermédias na jurisprudência constitucional portuguesa. In: Congresso luso-italiano de Direito Constitucional. Lisboa: Instituto de Ciências Jurídicopolíticas da Faculdade de Direito da Universidade de Lisboa, 2009.

ÁVILA, Humberto Bergmann. A distinção entre os princípios e regras e a redefinição do dever se proporcionalidade. Revista de Direito Administrativo, Rio de Janeiro, n. 215, pp. 151-179, jan/mar, 1999.

ÁVILA, Humberto. Teoria dos princípios. Da definição à aplicação dos princípios jurídicos. $4^{\mathrm{a}}$ ed. São Paulo: Malheiros, 2005.

\footnotetext{
${ }^{23}$ Referência a trecho de "crônica de uma morte anunciada".
} 
BARROSO, Luis Roberto. Interpretação e aplicação da Constituição. $7^{\mathrm{a}}$ ed. São Paulo: Saraiva, 2008.

BOBBIO, Norberto. Teoria do ordenamento jurídico. $6^{\mathrm{a}}$ ed. Brasília: Universidade de Brasília, 1995.

BONAVIDES, Paulo. Curso de Direito Constitucional. 13a ed. São Paulo: Malheiros, 2003.

BRASIL. Supremo Tribunal Federal (Plenário). ADI 6039 MC/RJ. Rel.: Min. Edson Fachin, 13 de março de 2019. Info. 933.

BRASIL. Supremo Tribunal Federal (1. Turma). Rcl 24284/SP. Rel.: Min. Edson Fachin, 22/11/2016. Info. 848.

BRASIL. Supremo Tribunal Federal. RP 1417. Rel.: Min. Moreira Alves, 15 de abril de 1988.

BRUST, Leo. A interpretação conforme a Constituição e as sentenças manipulativas. In: Revista Direito GV, São Paulo, v. 2, n. 5, p. 507-526, jul/dez, 2009.

CANOTILHO, José Joaquim Gomes. Direito Constitucional. $5^{\text {a }}$ ed. Almedina: Coimbra, 1995.

CAPPELLETTI, Mauro. El «formidable problema» del control judicial y La Contribución del Analisis Comparado. Revista de Estudios Políticos, [s. l.], n. 13, p. 61-104, 1980.

CLÈVE, Clémerson Mérlin. A fiscalização abstrata da constitucionalidade no Direito Brasileiro. $2^{a}$ ed. São Paulo: Revista dos Tribunais, 2000.

COELHO, Inocêncio Mártires. Métodos e princípios de interpretação constitucional. In: Revista de Direito Administrativo, Rio de Janeiro, 230, pp. 163-186, out/dez, 2002. Disponível em: https://edisciplinas.usp.br/pluginfile.php/. Acesso em: 20/02/2021.

DANTAS, Ivo. Constituição e Processo. Direito Processual Constitucional. $3^{\mathrm{a}}$ ed. Curitiba: Juruá, 2016.

DÍAZ REVORIO, Francisco Javier. Las sentencias interpretativas del Tribunal Constitucional: significado, tipología, efectos y legitimidad: análisis especial de las sentencias aditivas. México: Porrúa, 2011.

ENTERRÍA, Eduardo García de. La Constitución como norma y el Tribunal Constitucional. $2^{\mathrm{a}}$ ed. Madrid: Civitas, 1982.

FERRAZ JR., Tércio Sampaio. Introdução ao estudo do Direito. Técnica, decisão dominação. $10^{a}$ ed. São Paulo: Atlas, 2018.

GUASTINI, Riccardo. Das fontes às normas. Tradução: Edson Bini. São Paulo: Quatier Latin, 2005. 
GUASTINI, Riccardo. La constitucionalización del ordenamiento jurídico: el caso italiano. In: CARBONELL, Miguel (ed.). Neoconstitucionalismo(s). 4a ed. México: Trotta, 2009.

HABERLE, Peter. Hermenêutica Constitucional. A sociedade aberta dos intérpretes da Constituição: Contribuição para a interpretação pluralista e procedimental da Constituição. Porto Alegre: Fabrir Editor, 2002.

HESSE, Konrad. A força normativa da constituição. Tradução de Gilmar Ferreira Mendes. Porto Alegre: Sergio Antonio Fabris, 1991.

HESSE, Konrad. La interpretacion constitucional. In: HESSE, Konrad. Escritos de derecho constitucional. Tradução de Pedro Cruz Villalon. 2 ed. Madrid: Centro de Estudios Constitucionales, 1992.

JEFFERSON, Thomas. Carta a John Cartwright. 5 de junho de 1824. In: JEFFERSON, Thomas. Escritos Politicos. São Paulo: Ibrasa, 1964.

KELSEN, Hans. A garantia jurisdicional da Constituição (a justiça constitucional). Tradução Jean François Cleaver. Revista Direito Público, v. 1, n. 1, p. 90-130, 2003.

KELSEN, Hans. Jurisdição constitucional. Tradução de Maria Ermantina de Almeida Prado Galvão. $2^{a}$ ed. São Paulo: Martins Fontes, 2007.

LARENZ, Karl. Metodologia da Ciência do Direito. Lisboa: Fundação Calouste Gulbenkian, 1997.

LUNARDI, Soraya. Teoria do processo constitucional: análise de sua autonomia, natureza e elementos. São Paulo: Atlas, 2013.

MARINONI, Luiz Guilherme. Técnica processual e tutela dos direitos. $3^{\mathrm{a}}$ ed. São Paulo: Revista dos tribunais, 2010.

MÁRQUEZ, Gabriel García. Crônica de uma morte anunciada. Tradução de Remy Gorga Filho. Rio de Janeiro: Record, 1981.

MAXIMILIANO, Carlos. Hermenêutica e aplicação do direito. Rio de Janeiro: Forense, 1980.

MEDEIROS, Rui. A decisão de inconstitucionalidade: os autores, os conteúdos e os efeitos da decisão de inconstitucionalidade da lei. Lisboa: Universidade Católica, 1999.

MENDES, Gilmar Ferreira; COELHO, Inocêncio Mártires; BRANCO, Paulo Gustavo Gonet. Controle concentrado de constitucionalidade: comentários à lei n. 9.868, de 10-11-1999. $3^{\mathrm{a}}$ ed. São Paulo: Saraiva, 2009.

MIRANDA, Jorge. Contributo Para uma Teoria da Inconstitucionalidade. Coimbra: Coimbra Editora, 2008.

MORAIS, Carlos Blanco de. As sentenças com efeitos aditivos. In: MORAIS, Carlos Blanco de (coord.). As sentenças intermédias da justiça constitucional. Lisboa: AAAFDL, 2009. 
MORAIS, Carlos Blanco de. Justiça Constitucional. Tomo II. Coimbra: Coimbra Editora, 2005.

MULLER, Friedrich. Métodos de trabalho do direito constitucional. $3^{\mathrm{a}}$ ed. Rio de Janeiro: Renovar, 2005.

NADER, Paulo. Introdução ao estudo do Direito. 36 ed. Rio de Janeiro: Forense, 2014.

NEVES, Marcelo. A interpretação jurídica no estado democrático de direito. In: GRAU, Eros Roberto; GUERRA FILHO, Willis Santiago (eds.). Direito constitucional: Estudos em homenagem a Paulo Bonavides. São Paulo: Malheiros, 2001. p. 356-376.

PERELMAN, Chaim. Lógica jurídica: nova retórica. $2^{\mathrm{a}}$ ed. Traduzido por Virgínia K Pupi. São Paulo: Martins Fontes, 2004

POSNER, Richard. Statutory Interpretation - in the Classroom and in the Courtroom. University of Chicago Law Review, [s. l.] v. 50, p. 800-822, 1983.

REALE, Miguel. Lições preliminares de Direito. 27ª ed. São Paulo: Saraiva, 2002.

RIBEIRO, Julio de Melo. Controle de constitucionalidade das leis e decisões interpretativas. Revista de Informação Legislativa, Brasília, ano 46, n. 184, pp. 149-170, out/dez, 2009. Disponível em: https://www2.senado.leg.br/bdsf/item/id/242920. Acesso em 23/02/2021.

SILVA, José Afonso da. Curso de direito constitucional positivo. $24^{\mathrm{a}}$ ed. São Paulo: Malheiros Editores, 2004.

SILVA, Virgílio Afonso da. Interpretação constitucional e sincretismo metodológico. In: SILVA, Virgílio Afoso da. Interpretação constitucional. São Paulo: Malheiros, 2005. p. 115143.

SILVA, Virgilio Afonso da. La interpretación conforme a la Constitución. Entre la trivialidad y la centralización judicial. Cuestiones Constitucionales, [s. l.], n. 12, 2005.

SILVA, Virgílio Afonso da. Interpretação conforme a constituição: entre a trivialidade e a centralização judicial. Revista Direito GV, [s. l.], v. 2, n. 1, p. 191-210, 2006.

STRECK, Lenio Luiz. Jurisdição constitucional. Rio de Janeiro: Forense, 2018.

STRECK, Lenio Luiz. Súmulas no direito brasileiro: eficácia, poder e função. Porto Alegre: Livraria do Advogado, 1995.

URBANO, Maria Benedita. Curso de Justiça Constitucional. Evolução Histórica e Modelos de Controlo da Constitucionalidade. Coimbra: Almedina, 2014.

XAVIER, Marina Corrêa. O Supremo Tribunal Federal e os limites à interpretação conforme a Constituição. Dissertação de Mestrado. Faculdade de Direito, São Paulo: Universidade de São Paulo, 2013. Disponível em: <https://teses.usp.br/teses/>. Acesso em 25/02/2021. 


\section{DADOS DA PUBLICAÇÃO}

Categoria: artigo submetido ao double-blind review.

Recebido em: 17/03/2021.

Aceito em: 20/08/2021 